\title{
C. elegans TFIIH subunit GTF-2H5/TTDA is a non-essential transcription factor indispensable for DNA repair
}

Karen L. Thijssen ${ }^{1}$, Melanie van der Woude ${ }^{1}$, Carlota Davó-Martínez ${ }^{1}$, Mariangela Sabatella ${ }^{1,2}$, Wim Vermeulen ${ }^{1}$, Hannes Lans ${ }^{1, *}$

1. Department of Molecular Genetics, Oncode Institute, Erasmus MC, University Erasmus Medical Center Rotterdam, Dr. Molewaterplein 40, 3015 GD Rotterdam, The Netherlands

2. Present Address: Mariangela Sabatella, Princess Máxima Center for pediatric oncology, Heidelberglaan 25, 3584 CT, Utrecht

* Correspondence: w.lans@erasmusmc.nl 


\section{Abstract}

The 10-subunit TFIIH complex is vital to both transcription initiation and nucleotide excision repair. Hereditary mutations in its smallest subunit, TTDA/GTF2H5, cause a photosensitive form of the rare developmental brittle hair disorder trichothiodystrophy (TTD). Some TTD features are thought to be caused by subtle transcription or gene expression defects. Strikingly, TTDA/GTF2H5 knockout mice are not viable, which makes it difficult to investigate how TTDA/GTF2H5 promotes transcription in vivo. Here, we show that deficiency of the $C$. elegans TTDA ortholog GTF-2H5 is, however, compatible with viability and growth, in contrast to depletion of other TFIIH subunits. We also show that GTF-2H5 promotes the stability of TFIIH in multiple tissues and is indispensable for nucleotide excision repair, in which it facilitates recruitment of the TFIIH complex to DNA damage. Strikingly, when transcription is challenged, $g t f-2 \mathrm{H} 5$ embryos die due to the intrinsic TFIIH fragility in the absence of GTF-2H5. These results support the idea that TTDA/GTF2H5 mutations cause transcription impairment underlying trichothiodystrophy and establish C. elegans as potential model for studying the pathogenesis of this disease. 


\section{Introduction}

The general transcription factor TFIIH is an evolutionary conserved 10-subunit complex that has essential functions in transcription initiation and nucleotide excision repair (NER) (Compe \& Egly, 2016). It consists of a core complex comprised of subunits XPB/ERCC3, XPD/ERCC2, p62/GTF2H1, p44/GTF2H2, p34/GTF2H3, p52/GTF2H4 and p8/TTDA/GTF2H5 and the cyclin-activating kinase (CAK) complex consisting of MAT1/MNAT1, CDK7 and Cyclin H/CCNH (Luo et al, 2015). In RNA polymerase II (Pol II)-driven transcription initiation, TFIIH binds the promoter and, stimulated by TFIIE (Compe et al, 2019; Ohkuma \& Roeder, 1994), facilitates promoter escape and RNA synthesis by DNA helix opening using its XPB helicase/translocase subunit (Coin et al, 1999; Tirode et al, 1999; Fishburn et al, 2015) and by phosphorylating the C-terminal domain of RPB1, the largest Pol Il subunit, via its CDK7 subunit (Lu et al, 1992). TFIIH is furthermore thought to function in RNA Pol I transcription (Hoogstraten et al, 2002; Iben et al, 2002) and to regulate the recruitment and/or activity of various transcriptional regulators (Keriel et al, 2002; Singh et al, 2015). In NER, TFIIH functions in both the global genome (GG-NER) and the transcription-coupled (TC-NER) subpathway. GG-NER repairs helix-distorting single-stranded DNA lesions anywhere in the genome, whereas TC-NER repairs any lesion that blocks elongating Pol II (Marteijn et al, 2014; Schärer, 2013). TFIIH is recruited to lesions upon DNA damage detection and, together with NER factor XPA, opens the DNA using its XPD helicase subunit, thereby verifying the presence of damage and providing a substrate for downstream endonucleases ERCC1/XPF and XPG to cut out the damaged DNA (Sugasawa et al, 2009; Winkler et al, 2000). These essential functions of TFIIH are conserved from yeast to humans.

Mutations in the individual subunits of TFIIH cause several diseases characterized by growth and neurodevelopmental failure (Lehmann, 2003; Ferri et al, 2020). Mild mutations in XPB and XPD, which only affect TFIIH function in GG-NER, cause xeroderma pigmentosum, which is characterized by sun 
sensitivity and cancer susceptibility. More disruptive mutations in these subunits additionally cause Cockayne syndrome (CS) features, such as growth failure and progressive neurodegeneration, of which the exact pathogenesis is still debated and not fully understood. We proposed that specific impairment of TC-NER, in combination with prolonged lesion stalling of Pol II or the NER core complex, causes or contributes to CS features (Lans et al, 2019; Sabatella et al, 2018). However, other causes such as specific transcriptional or mitochondrial defects have been put forward (Wang et al, 2014; Karikkineth et al, 2017). A third group of mutations in XPB and XPD, likely those affecting also TFIIH transcription function, cause a photosensitive form of trichothiodystrophy (TTD), which is furthermore characterized by brittle hair and nails, ichthyosis and progressive mental and physical retardation (Hashimoto \& Egly, 2009; Faghri et al, 2008). Besides XPB and XPD, only mutations in TTDA, the smallest subunit of TFIIH, have thus far been associated with photosensitive TTD (Giglia-Mari et al, 2004). Mutations in XPB, XPD and TTDA are rare and often found in compound heterozygous combinations. This, and the fact that so far only patients with mutations in three out of ten TFIIH subunits have been identified, reflects the fact that the TFIIH complex is essential for life (Park et al, 1992; De Boer et al, 1998; Theil et al, 2013; Andressoo et al, 2009).

In mice, disruption of XPD leads to embryonic lethality at the two-cell stage (De Boer et al, 1998). In contrast to other TFIIH subunits, yeast strains (Ranish et al, 2004) and mouse embryonic stem cells and fibroblasts (Theil et al, 2013) with complete inactivation of TTDA are viable, suggesting that TTDA is not essential for TFIIH basal transcription function. However, also disruption of TTDA leads to embryonic lethality in mice, albeit that embryos survive almost up to birth (Theil et al, 2013). Rare human TTD patients carry missense or nonsense mutations in TTDA that do not completely disrupt TTDA but lead to expression of a partially functional protein (Theil et al, 2011, 2013). This suggests that although TTDA appears to be less essential for transcription than other TFIIH subunits, full TTDA loss is not compatible with development of multicellular life (Theil et al, 2013; Moriwaki et al, 2014; Nonnekens et al, 2013). It 
is currently unclear why TTDA appears dispensable for transcription and viability of single cell systems but not of multicellular organisms and certain differentiated tissues.

The nematode $C$. elegans conserves many features of mammalian transcription and DNA repair (Bowman \& Kelly, 2014; Boulton et al, 2002). We and others have previously shown that NER is conserved and protects genome integrity in germ cells and transcriptional integrity in somatic cells against DNA damage induced by UV light and other environmental and metabolic sources (Lans et al, 2010; Lans \& Vermeulen, 2011, 2015; Astin et al, 2008; Rieckher et al, 2017; Meyer et al, 2007). Thus far, the composition and activity of $C$. elegans TFIIH has not been addressed. Here, we focus specifically on the $C$. elegans TTDA ortholog GTF-2H5 and show that this TFIIH factor is dispensable for development and viability under normal, unchallenged laboratory culture conditions. However, GTF-2H5 is essential for TFIIH stability and genome maintenance via NER and becomes vital to transcription when this is challenged. 


\section{Results and discussion}

\section{C. elegans lacking TTDA/GTF-2H5 is viable}

To study the function of TTDA/GTF2H5 in C. elegans, we characterized animals carrying a deletion mutation (tm6360) in the orthologous $\mathrm{gtf}-2 \mathrm{H} 5$ gene. This gene only consists of two exons and is predicted to encode a 71 amino acid protein with an estimated molecular weight of $8.2 \mathrm{kD}$, which is similar as its human TTDA ortholog with which it shares $45 \%$ sequence identity. The tm6360 allele was obtained from the National Bioresource Project for the nematode (Mitani, 2009) and represents a deletion of the entire second exon and flanking sequences (Fig 1A). By RT-PCR and RT-qPCR of the mRNA, we confirmed that $g t f-2 \mathrm{H} 5$ mutants do not express the second exon but found that the first exon is still expressed, albeit at $>70 \%$ reduced levels (Fig 1B and C; Fig EV1A). To confirm whether indeed the tm6360 allele encodes a truncated protein, we determined by PCR and sequencing of cDNA whether a mutated mRNA was being produced. In the $g t f-2 \mathrm{H} 5$ mutant, we detected by PCR a cDNA fragment stretching from the first exon of gtf-2H5 (primer 1 in Fig $1 \mathrm{~A}$ ) to the last exon of the downstream B0353.1 gene (primer 4 in Fig 1A; Fig EV1B), which after sequencing revealed that $g t f-2 H 5$ mutants carrying the $t m 6360$ allele express low levels of a mutant mRNA consisting of the first gtf-2H5 exon fused to the reverse sequence of the last exon of B0353.1 (Fig EV1C). Gene prediction by FGENESH (Salamov \& Solovyev, 2000) indicated that this mRNA encodes a mutated GTF- $2 \mathrm{H} 5$ protein of which the C-terminal half is deleted and replaced by nonsense amino acid sequence (Fig 1D). Thus, tm6360 is likely a strong loss-of-function allele.

TFIIH consists of ten subunits that are all conserved in C. elegans (Table 1) (Lans \& Vermeulen, 2011) and which are all essential to life in mammals, including TTDA (Park et al, 1992; De Boer et al, 1998; Theil et al, 2013; Andressoo et al, 2009). Strikingly, we found that gtf-2H5 mutants were viable, showed no embryonic lethality and produced similar brood size as wild type animals (Table 2). To test whether this might be due to the weakly expressed truncated GTF-2H5 protein being still partially functional, we 
examined whether full depletion of GTF-2H5 is lethal for $C$. elegans. To this end, we fused an auxininducible degradation (AID) tag (Zhang et al, 2015) together with GFP to GTF-2H5 by knocking in both tags at the C-terminus of the gtf-2H5 gene using CRISPR/Cas9 (Fig 2A). As comparison, we also knocked in AID and GFP at the N-terminus of $g$ tf-2H1 (Fig 2B), the C. elegans ortholog of TFIIH subunit GTF2H1/p62, which in humans and yeast is essential for TFIIH integrity and function (Luo et al, 2015; Ribeiro-Silva et al, 2018; Barnett et al, 2020; Fischer et al, 1992). For simplicity, we will refer to the AID::GFP tag with 'AG' and to these knockin animals as $g t f-2 H 5:: A G$ and $A G:: g t f-2 H 1$. Both knockin animals were fully viable and similarly expressed AG-tagged TFIIH in nuclei of all tissues (Fig 2C; Fig EV1D). Also, both transgenic animals displayed normal, wild type UV survival in an assay that measures TC-NER (Fig EV2A) (Lans et al, 2010; van der Woude \& Lans, 2021), indicating that the TFIIH complex is intact and functional when either GTF-2H5 or GTF-2H1 is tagged. We crossed both strains with animals expressing Arabidopsis TIR1 (fused to mRuby) specifically in germ cells and early embryos under control of the sun-1 promoter (Zhang et al, 2015; Minn et al, 2009). Exposure to auxin, which activates the TIR1 E3 ubiquitin ligase complex that ubiquitylates the AID tag, led to full depletion of both fusion proteins in the germline (Fig EV2B). However, only the depletion of AID-tagged GTF-2H1, and not that of GTF-2H5, caused complete embryonic lethality (Fig 2D and E). Previously, we also showed that auxin-induced depletion of the TFIIH subunit XPB-1 causes developmental arrest (Sabatella et al, 2021). As animals with truncated or depleted GTF-2H5 do not show any embryonic lethality, we conclude that unlike other TFIIH subunits, GTF-2H5 is not essential for embryogenesis and viability in C. elegans.

GTF-2H5 promotes TFIIH stability in multiple tissues in vivo

Both GTF-2H5 as well as GTF-2H1 showed exclusive nuclear expression in various tissues of $C$. elegans (Fig EV1D). To have an idea of the concentration of TFIIH molecules present in vivo in nuclei of different tissues, 
we determined GTF-2H5::AG and AG::GTF-2H1 concentrations in several readily visible tissues by carefully comparing average nuclear fluorescence signals to that of known GFP concentrations. This showed comparable concentrations of around $0.2 \mu \mathrm{M}$ for GTF-2H1 in oocyte, hypodermal, intestinal and muscle nuclei (Fig 2F), which is strikingly similar to concentration estimations made of Pol II in human fibroblasts $(0.18 \mu \mathrm{M})$ using a similar method (Steurer et al, 2018). GTF-2H5 concentrations were mostly similar, but showed higher variation between individual nuclei and a lower concentration in muscle cells. This may reflect the notion that this factor can dynamically associate with TFIIH (Giglia-Mari et al, 2006). We quantified TFIIH concentration in brightly fluorescent cells that were easily discernable, but noticed that in many other nuclei, such as for instance in head neurons, expression levels seemed much lower (Fig EV1D). As nuclei in neurons are smaller than those in oocytes, hypodermal and intestinal cells, the TFIIH concentration will also be lower in these cell types. Similar analysis of mouse XPB-YFP fluorescence levels in tissues of XPB-YFP knockin mice also showed that TFIIH levels vary depending on the cell type, which, interestingly, was found to correlate to transcriptional activity in these cells (Donnio et al, 2019). Thus, possibly also in C. elegans TFIIH levels can be used as quantitative biomarker of transcriptional activity. This correlation, however, is difficult to prove as quantification of nascent mRNA by 5-ethynyl uridine labeling in different tissues of $C$. elegans does not produce sufficiently reproducible results in our hands (Sabatella et al, 2021).

To determine the impact of GTF-2H5 loss on TFIIH levels, we crossed $A G:: g f t-2 H 1$ animals with gtf-2H5 mutants and found that loss of GTF-2H5 led to reduced levels of AG::GTF2H1 in all tested tissues by more than 50\% (Fig 2F). These results are in line with lowered TFIIH protein levels observed in patient and mouse fibroblasts (Theil et al, 2013; Botta et al, 2002), while TFIIH subunit mRNA levels are unaffected (Vermeulen et al, 2000), and indicate that GTF-2H5 has an evolutionary conserved function in maintaining steady state levels of TFIIH, not only in vitro but also in various tissues in vivo. 


\section{GTF-2H5 is essential for nucleotide excision repair}

Because of the lowered TFIIH levels, we tested whether specific functions of TFIIH were affected and first

focused on its role in NER. We and others have previously shown that UV-induced DNA damage causes embryonic lethality in the absence of GG-NER (Lans et al, 2010; Lans \& Vermeulen, 2015; Astin et al, 2008;

van der Woude \& Lans, 2021). We observed that $g t f-2 H 5$ mutants are as sensitive to UV-induced DNA damage as NER-deficient xpa-1 mutants, showing severe embryonic lethality upon UV irradiation (Fig 3A).

These results indicate that the tm6360 allele is a null allele with respect to GTF-2H5 function in NER.

To gain further insight into the cause of UV hypersensitivity of gtf- $2 \mathrm{H} 5$ mutant animals, we visualized recruitment of TFIIH to DNA damage. In C. elegans oocytes, DNA is condensed and organized into six pairs of bivalents, i.e., paired homologous chromosomes, that are readily discernable by microscopy e.g. when stained with DAPI (Fig EV2C, left panel). We showed previously that upon UV irradiation, the NER endonuclease ERCC-1/XPF-1 rapidly re-localizes from the nucleoplasm to damaged chromosomes, reflecting its activity in NER (Sabatella et al, 2021). This damaged-DNA binding is dependent on GG-NER and lasts for approximately half an hour until UV photolesions are repaired and NER is completed. In line with this, we observed clear re-localization of both GTF-2H5::AG and AG::GTF-2H1 to oocyte bivalents 10 min after UV irradiation, while imaging living (Fig 3B) or fixed (Fig EV2C) animals, reflecting TFIIH binding to UV-damaged DNA. This recruitment was not observed anymore $35 \mathrm{~min}$ after UV, indicating completion of repair, as previously shown (Sabatella et al, 2021). Next, we tested re-localization of AG::GTF-2H1 in gtf-2H5 mutants and strikingly observed that its UV-induced recruitment to damaged chromosomes was strongly reduced after $10 \mathrm{~min}$ and persisted after $35 \mathrm{~min}$ (Fig 3B). We observed similar $\mathrm{gtf}$-2H5-dependent recruitment to damaged bivalents of another TFIIH subunit, XPB-1 (Fig EV2D), of which we previously had generated AID::GFP knockin animals (Sabatella et al, 2021). Together with the strong UV hypersensitivity of $g t f-2 \mathrm{H} 5$ mutants, these results indicate that GTF- $2 \mathrm{H} 5$ is needed for efficient binding of TFIIH to damaged 
DNA and that in absence of GTF-2H5 repair cannot be completed. Also in vitro and in cultured mammalian cells TTDA was found to be essential for NER and the recruitment of TFIIH to sites of UV-induced DNA damage, likely by stimulating XPB ATPase activity and TFIIH translocase activity together with XPC and XPA (Theil et al, 2013; Giglia-Mari et al, 2004; Coin et al, 2006; Kappenberger et al, 2021). Our results show that GTF-2H5 has a similar, evolutionary conserved role in stimulating TFIIH activity in NER in oocytes of C. elegans. Besides NER, TTDA has been implicated in repair of oxidative DNA damage, as TTDA knockout mouse embryonic stem cells are sensitive to ionizing radiation and $\mathrm{KBrO}_{3}$ (Theil et al, 2013). However, when comparing $\mathrm{KBrO}_{3}$ sensitivity of $C$. elegans gtf- $2 \mathrm{H} 5$ mutants and wild type animals, we did not observe any obvious hypersensitivity (Fig 3C).

Since $g t f-2 H 5$ mutants are as UV hypersensitive as $x p a-1$ mutants, we tested whether these animals also exhibit phenotypes that we previously reported to be caused by accumulating DNA damage and mutations due to NER deficiency. A significant proportion of $C$. elegans NER deficient animals in a population exhibit growth delay due to spontaneous DNA damage (Lans et al, 2013). Indeed, we observed that a percentage of $g t f-2 \mathrm{H} 5$ animals exhibited delayed development, just as $x p a-1$ animals, in comparison to wild type (Fig 3D). Also, we previously showed that NER mutants do not have reduced postmitotic lifespan, i.e. longevity measured from the onset of adulthood, but do show severely reduced replicative lifespan, i.e. transgenerational replicative capacity (Lans et al, 2013). We confirmed again that xpa-1 mutants have a postmitotic lifespan comparable to wild type animals (Fig 3E), but that their ability to proliferate and reproduce over generations strongly declines (Fig 3F). To our surprise, however, we found that gtf-2H5 mutants show both a shortened postmitotic (Fig 3E) and replicative (Fig 3F) lifespan, which appear both more reduced than of xpa-1 mutants. Thus, besides being clearly NER defective, gtf-2H5 animals likely carry a defect in an additional biologic pathway that causes them to live shorter. 
GTF-2H5 is required for transcription when this is challenged

TTD patients with mutations in TTDA, XPB and XPD exhibit typical TTD features like brittle hair and nails and ichthyosis and, in addition, photosensitivity and progressive neuropathy that are reminiscent of xeroderma pigmentosum (Hashimoto \& Egly, 2009; Faghri et al, 2008). Photosensitivity and part of the neuropathy are considered to be due to defects in NER, but the other features are thought to be caused by limited availability of TFIIH, due to its instability and lowered levels that lead to its exhaustion in terminally differentiated cells, such as skin and hair keratinocytes, before the transcriptional program in these cells has ended (De Boer et al, 1998b; Theil et al, 2014). As TFIIH is needed for transcription of abundant proteins in these cells, such as cysteine-rich matrix proteins, reduced amounts of TFIIH likely explain the sulfur-deficient brittle hair and nails and scaly skin features. Thus, we postulate that, similarly, the lowered TFIIH levels in $g t f-2 H 5$ animals lead to TFIIH exhaustion and limited TFIIH availability for transcription initiation in older animals, causing cell dysfunction and reduced lifespan.

To test whether the lowered TFIIH amounts in $g t f-2 \mathrm{H} 5$ animals indeed become restrictive in circumstances with altered transcriptional demand, we tested whether a transcription defect might become apparent in these animals when transcription is challenged. As transcription cannot be reliably measured with 5ethynyl uridine labeling, we crossed $g t f-2 \mathrm{H} 5$ mutants with animals expressing GFP in body muscle cells under control of the eft-3 promoter (Zhang et al, 2015), and quantified GFP fluorescence levels as proxy for transcriptional competence (Sabatella et al, 2021). This showed no difference between wild type and gtf-2H5 animals (Fig 4A and B), indicating that in unperturbed conditions gtf-2H5 animals are fully transcriptionally competent for this muscle-specific transgene.

Next, we compromised transcription by limiting the availability of another transcription initiation factor, without compromising NER. To this end, we cultured wild type and gtf-2H5 animals on gtf-2E1 RNAi bacteria to diminish protein levels of the essential TFIIE transcription factor complex, which stimulates 
TFIIH activity and helps anchor it within the Pol II pre-incision complex, but has no role in NER (Yamamoto et al, 2001; Compe et al, 2019; Ohkuma \& Roeder, 1994; Theil et al, 2017; Kuschal et al, 2016; Park et al, 1995).gtf-2E1 RNAi food is not fully efficient and causes only partial knockdown of $g t f-2 E 1$ transcripts and therefore only mild embryonic lethality in wild type animals (Fig $4 \mathrm{C}$ and D). Strikingly, however, gtf-2H5 animals grown on the same gtf-2E1 RNAi food showed very high levels of embryonic lethality. By measuring GFP fluorescence in body wall muscles, we observed that partial gtf-2E1 knockdown lowered GFP proteins levels in wild type animals, which was further enhanced in gtf- $2 \mathrm{H} 5$ animals (Fig $4 \mathrm{~A}$ and E). Thus, in conditions of limited availability of the TFIIE transcription factor and lowered gene expression, GTF-2H5 becomes essential for transcription efficiency and viability. To confirm this in another way, we measured the transcript levels of two housekeeping genes, $c d c-42$ and $p m p-3$, by qPCR in cDNA generated from RNA isolated from the same amount of non-gravid adult wild type or gtf- $2 \mathrm{H} 5$ animals grown on control or gtf-2E1 RNAi. This showed that $g f t-2 H 5$ knockout or gtf2E1 knockdown alone did not result in lowered transcript levels, but the combined loss of $g t f-2 \mathrm{H} 5$ and $g t f-2 E 1$ strongly reduced transcription of both housekeeping genes (Fig 4F and G). These results therefore suggest that in C. elegans GTF-2H5 (and thus high steady-state TFIIH levels) is dispensable for transcription throughout most of $C$. elegans lifespan in unperturbed laboratory culturing conditions, but becomes essential for transcription if this process is somehow compromised or challenged.

This notion may explain contradicting results in previous studies of TTDA's importance to transcription. Initially, upon its identification, human TTDA was considered a NER-specific TFIIH factor dispensable for transcription. TTD-A patient cells had no obvious transcriptional defects and purified TTDA did not stimulate TFIIH-dependent transcription in vitro (Vermeulen et al, 2000; Giglia-Mari et al, 2006; Coin et al, 2006; Kainov et al, 2008). However, TTDA knockout mouse embryonic stem cells did show reduced transcription levels (Theil et al, 2013) and a reconstituted transcription assay using different recombinant TFIIH also showed that transcription was stimulated by TTDA (Aguilar-Fuentes et al, 2008). Furthermore, 
yeast lacking TTDA ortholog TFB5 did not show any major change in gene expression as observed by microarray, but still TFB5 was found to stimulate transcription in vitro and efficient transcription in vivo when there was high demand such as in changing environmental conditions (Ranish et al, 2004). Thus, it appears that depending on the particular conditions of the assay or cell type used, contingent on transcriptional demand, the absence of TTDA/GTF-2H5 may or may not be a limiting factor. This feature may explain why cultured yeast and mammalian cells and C. elegans can thrive without TTDA/GTF-2H5, whereas mice with full TTDA loss are not viable, likely because mammalian embryogenesis requires high transcriptional capacity (Theil et al, 2014).

High resolution cryo-EM structures of the human preinitiation complex do not suggest a direct role for TTDA in loading or DNA interaction of TFIIH at promoters (Aibara et al, 2021). Therefore, to test whether the importance of GTF-2H5 for compromised transcription is due to its ability of stabilizing TFIIH, we tested if lowering TFIIH levels in another way, by partially depleting the TFIIH subunit GTF-2H2C (p44/GTF2H2 in humans; Table 1), led to similar enhanced embryonic lethality when transcription is compromised. To this end, we cultured wild type animals on an equal mixture of control RNAi and gtf2H2C RNAi food, which destabilized TFIIH, as visualized by lowered AG::GTF-2H1 levels (Fig 5A), and caused incompletely penetrant embryonic lethality (Fig 5B). However, when gtf-2H2C RNAi food was equally mixed with gtf-2E1 RNAi food, this led to very high levels of embryonic lethality. These results confirm that unstable and lowered levels of TFIIH compromise transcription when this is challenged.

gtf-2H5 C. elegans mutants as model for trichothiodystrophy

TFIIH is an essential transcription and DNA repair factor. While thus far all TFIIH subunits were thought to be essential to multicellular life, including TTDA/GTF2H5, here we show that $C$. elegans strains with 
truncated or complete depletion of GTF-2H5 are viable. As gtf-2H5 mutants are strongly UVhypersensitive, similar as xpa-1 loss-of-function mutants, and show impaired recruitment of TFIIH to UVinduced DNA damage, GTF-2H5 is an essential NER factor (Fig 5C). With the characterization of GTF-2H5 presented in this study, and with it of the entire TFIIH complex, we and others have shown full functional conservation of both the GG- and TC-NER pathway in C. elegans (Astin et al, 2008; Babu \& Schumacher, 2016; Babu et al, 2014; Lans et al, 2010, 2013; Lans \& Vermeulen, 2011; Geijer et al, 2021; Lee et al, 2002; Park et al, 2004; Stergiou et al, 2007; Sabatella et al, 2021; Hartman et al, 1989; Meyer et al, 2007).

In recent years, besides mutations in XPB, XPD and TTDA, multiple additional mutations in genes have been identified to cause TTD or TTD-like syndromes, among which are mutations in transcription initiation factor TFIIE, which all affect the stability of proteins involved in different steps of transcription and translation (Kuschal et al, 2016; Theil et al, 2017; Botta et al, 2021; Kuo et al, 2019; Theil et al, 2019; Tessarech et al, 2020; Corbett et al, 2015). Together, these have put forward the unifying idea that TTD is caused by instability of proteins involved in gene expression. Our results are in line with this idea and confirm that loss of GTF-2H5 leads to instability of the transcription initiation factor TFIIH, which may lead to transcription problems in cells of aged animals due to TFIIH exhaustion (Fig 5C). Furthermore, we find that when transcription initiation is hampered, by lowering of TFIIE levels, the reduced TFIIH levels in gtf$2 \mathrm{H} 5$ mutants become restrictive and cause strong embryonic lethality. Thus, in contrast to its function in NER, TTDA appears mostly dispensable for TFIIH function in facilitating transcription initiation by RNA polymerase I and II. However, in conditions of transcription stress, when there is demand for high TFIIH concentrations due to e.g high transcriptional output or reduced availability of other transcription initiation factors, the TFIIH-stabilizing ability of TTDA becomes essential to ensure sufficiently high TFIIH levels for transcription to initiate. These findings indicate that gtf-2H5 mutant $\mathrm{C}$. elegans can be an advantageous multicellular animal model for studying genetic and developmental pathogenic aspects of TTD features. 


\section{Material and methods}

\section{C. elegans strains and culture}

C. elegans strains used are listed in Table EV1. C. elegans was cultured according to standard methods on nematode growth media (NGM) agar plates seeded with Escherichia coli OP50. All mutants were backcrossed against wild type strain, which was Bristol N2. gtf-2H5::AG knockin animals were generated using gRNA with targeting sequence CATGGAAAATATGAATCCGG and as homology directed repair template a heteroduplex DNA fragment generated by mixing PCR products (Dokshin et al, 2018) obtained with primers combinations 5'-GAACTCGACGATACGCATTTG-3'/5'-GCCTAAAACATGAAGCCTGTTG-3' and 5'-GTATCCTTCAATCCACCGTTC-3'/5'-TTTGTATAGTTCGTCCATGCC-3' on a gene fragment consisting of AID::GFP sequences flanked by 200 bp homology arms from the gtf-2H5 locus. AG::gtf-2H1 knockin animals were generated using gRNA with targeting sequence TTTTCAGATGTCAGACGAGT and as homology directed repair template a gene fragment consisting of AID::GFP sequences flanked by 100 bp homology arms from the gtf-2H1 locus in pUCIDT-KANA (Integrated DNA technologies). sgRNA and plasmids were injected in the Cas9dPiRNA expressing strain HCL67 (a kind gift from Heng-Chi Lee) (Zhang et al, 2018). Knockin animals were verified by genotyping PCR and sequencing, after which the Cas 9 was removed by backcrossing against wild type. RNAi bacteria were obtained from the Caenorhabditis elegans RNAi feeding library (Kamath et al, 2003). Control RNAi was vector pPD129.36 (a gift from Andrew Fire).

Brood size, growth and embryonic lethality

To measure brood size, L4 animals were individually seeded and transferred to a new culture plate every day, after which eggs laid were counted. To measure growth, adult animals were allowed to lay eggs for $4 \mathrm{~h}$. After $48 \mathrm{~h}$ at $25^{\circ} \mathrm{C}$, the growth of the progeny was scored by counting the amount of adult, L4 and 
younger than L4 animals. To measure embryonic lethality of AID-tagged transgenic strains, late L4 animals were mock treated or exposed to $1 \mathrm{mM}$ auxin (3-indoleacetic acid, Sigma) for $24 \mathrm{~h}$. To measure embryonic lethality of RNAi-fed strains, animals were first grown for one generation on RNAi food. Next, four animals per plate were allowed to lay eggs for $3 \mathrm{~h}$, after which hatched and unhatched eggs were scored.

\section{Lifespan assays}

To measure post-mitotic lifespan, standard longevity assays were performed at $20^{\circ} \mathrm{C}$ as previously described with day 1 defined as the day when animals reached adulthood (Lans \& Jansen, 2007). Animals were scored every 1 to 3 days. To measure transgenerational replicative lifespan, assays were performed as previously described (Lans et al, 2013). In brief, 15 animals per strain were individually seeded and cultured to produce progeny at $25^{\circ} \mathrm{C}$. From each progeny, a single animal was randomly picked, transferred to a fresh culture plate and grown to produce new offspring, which was repeated for 15 generations. Progeny was considered to have lost viability if animals arrested development, produced no or inviable progeny or died before reproduction. Animals that crawled off the plate were censored.

\section{$R T-P C R$ and $R T-q P C R$}

For RT-PCR, animals were lysed in TRIzol (Qiagen) and RNA was purified using RNeasy spin columns (Qiagen). cDNA was generated using Superscript II Reverse Transcriptase (Invitrogen) according to manufacturer's instructions. For RT-qPCR, RNA was isolated and cDNA generated from 10 young adult animals per strain and condition using the Power SYBR Green Cells-to-Ct kit (Invitrogen) according to the method described by Chauve et al (Chauve et al, 2020). qPCR was performed using PowerUp SYBR Green Master Mix (Invitrogen), according to manufacturer's instructions, with $58^{\circ} \mathrm{C}$ as annealing temperature 
and 1 min elongation time. Primers used for RT-PCR and RT-qPCR are listed in Table EV2. cdc-42 and pmp3 cDNA were used as reference genes, unless otherwise stated.

Imaging and GTF-2H5 and GTF-2H1 concentration measurements.

For microscopy of living animals, animals were mounted on $2 \%$ agar pads in $\mathrm{M} 9$ containing $10 \mathrm{mM} \mathrm{NaN}_{3}$ (Sigma) and imaged on a Zeiss LSM700 or Leica SP8 confocal microscope. For microscopy of fixed animals, animals were fixed on Poly-L-lysine hydrobromide (Sigma) slides with $4 \%$ paraformaldehyde in PBS and slides were mounted using Vectashield with DAPI (Vector laboratories). Fluorescence intensities of AID::GFP driven by eft-3 promoter in head body wall muscles were imaged and quantified using ImageJ software. To estimate concentrations of GTF-2H5::AG and AG::GTF-2H1, we imaged GFP fluorescence intensity of Z-slices of individual nuclei of the indicated cell-types. Average fluorescence intensities of each nucleus were then calibrated to fluorescence intensities of different concentrations of purified eGFP (Biovision), using similar imaging condition, to derive the protein concentration.

\section{Survival assays}

UV survival was carried out as described (Lans et al, 2010; van der Woude \& Lans, 2021). For UV irradiation, Philips TL-12 UV-B tubes (40W) were used. To determine UV-induced embryonic lethality in Fig 3A, staged young adult worms were washed, UVB-irradiated on agar plates without food and allowed to recover for $24 \mathrm{~h}$ on plates with OP50 bacteria. Next, five adults were allowed to lay eggs for $3 \mathrm{~h}$ on 6 $\mathrm{cm}$ plates seeded with HT115 bacteria, in five-fold for each UVB dose and $24 \mathrm{~h}$ later, the amount of hatched and unhatched (dead) eggs was counted. To determine UV-induced larval growth arrest in Fig EV2A, eggs were collected by hypochlorite treatment of adult animals and plated onto agar plates with HT115 bacteria. After 16 h, L1 larvae were UVB-irradiated and allowed to recover for $48 \mathrm{~h}$. Survival was 
determined by counting animals arrested at the L1/L2 stages and animals that developed beyond the L2 stage. To determine $\mathrm{KBrO}_{3}$ sensitivity, eggs were collected by hypochlorite treatment and allowed to hatch in $\mathrm{S}$ basal medium containing OP50 bacteria for $16 \mathrm{~h}$ at $21^{\circ} \mathrm{C}$ while shaking. Next, the indicated $\mathrm{KBrO}_{3}$ concentrations were added to the liquid cultures, in triplicate. After $24 \mathrm{~h}$ incubation, animals were plated on $6 \mathrm{~cm}$ culture plates seeded with HT115 bacteria and incubated at $15^{\circ} \mathrm{C}$. After a recovery period of 72 $h$, the number of arrested animals at the L1/L2 stages and animals that developed beyond the L2 stage were counted. Survival percentages was calculated by dividing the number of arrested larvae by the total amount of animals.

\section{Statistics}

Prism GraphPad was used to calculate statistical differences. For the survival experiments in Figure $3 E$ and F a Log-rank (Mantel-Cox) test was used and for statistical significance between groups one-way ANOVA followed by post hoc analysis by Bonferroni's test was used. 


\section{Acknowledgements}

We thank Dr. A. Theil for advice, Dr. G. Jansen for use of his injection microscope, Dr. Heng-Chi Lee and

Dr. Andrew Fire for strains and plasmids and Dr. G. van Cappellen and the Erasmus MC Optical Imaging Center for microscope support. Some strains were provided by the Caenorhabditis Genetics Center (funded by NIH Office of Research Infrastructure Programs P40 OD010440) and the National Bioresource Project for the nematode. This work was supported by the Netherlands Organization for Scientific Research (711.018.007 and ALWOP.494), the Marie Curie Initial Training Network "aDDRess" funded by the European Commission 7th Framework Programme (316390), the European Research Council (advanced grant 340988-ERC-ID), and the gravitation program CancerGenomiCs.nl from the Netherlands Organization for Scientific Research. Oncode Institute is partly financed by the Dutch Cancer Society.

\section{Author contribution}

KLT, MvdW, CD, MS and HL performed experiments and analyzed data. KLT, MvdW, WV and HL designed experiments. MvdW, WV and $\mathrm{HL}$ wrote the manuscript. All authors reviewed the manuscript.

\section{Conflict of interest}

The authors declare that they have no conflict of interest. 


\section{References}

Aguilar-Fuentes J, Fregoso M, Herrera M, Reynaud E, Braun C, Egly JM \& Zurita M (2008) p8/TTDA overexpression enhances UV-irradiation resistance and suppresses TFIIH mutations in a Drosophila trichothiodystrophy model. PLoS Genet 4: e1000253

Aibara S, Schilbach S \& Cramer P (2021) Structures of mammalian RNA polymerase II pre-initiation complexes. Nature 594: 124-128

Andressoo J-O, Weeda G, de Wit J, Mitchell JR, Beems RB, van Steeg H, van der Horst GTJ \& Hoeijmakers JH (2009) An Xpb Mouse Model for Combined Xeroderma Pigmentosum and Cockayne Syndrome Reveals Progeroid Features upon Further Attenuation of DNA Repair. Mol Cell Biol 29: 1276-1290

Astin JW, O'Neil NJ \& Kuwabara PE (2008) Nucleotide excision repair and the degradation of RNA pol II by the Caenorhabditis elegans XPA and Rsp5 orthologues, RAD-3 and WWP-1. DNA Repair (Amst) 7: $267-280$

Babu V, Hofmann K \& Schumacher B (2014) A C. elegans homolog of the Cockayne syndrome complementation group A gene. DNA Repair (Amst) 24: 57-62

Babu V \& Schumacher B (2016) A C. elegans homolog for the UV-hypersensitivity syndrome disease gene UVSSA. DNA Repair (Amst) 41: 8-15

Barnett JT, Kuper J, Koelmel W, Kisker C \& Kad NM (2020) The TFIIH subunits p44/p62 act as a damage sensor during nucleotide excision repair. Nucleic Acids Res 48: 12689-12696

De Boer J, Donker I, De Wit J, Hoeijmakers JHJ \& Weeda G (1998) Disruption of the mouse xeroderma pigmentosum group D DNA repair/basal transcription gene results in preimplantation lethality. Cancer Res 58: 89-94 
Botta E, Nardo T, Lehmanni AR, Egly JM, Pedrini, Antonia M \& Stefanini M (2002) Reduced level of the repair/transcription factor TFIIH in trichothiodystrophy. Hum Mol Genet 11: 2919-2928

Botta E, Theil AF, Raams A, Caliguri G, Giachetti S, Bione S, Accadia M, Lombardi A, Smith DECC, Mendes MI, et al (2021) Protein instability associated with AARS1 and MARS1 mutations causes Trichothiodystrophy. Hum Mol Genet: doi: 10.1093/hmg/ddab123

Boulton SJ, Gartner A, Reboul J, Vaglio P, Dyson N, Hill DE \& Vidal M (2002) Combined functional genomic maps of the C. elegans DNA damage response. Science (80- ) 295: 127-131

Bowman EA \& Kelly WG (2014) RNA Polymerase II transcription elongation and Pol II CTD Ser2 phosphorylation: A tail of two kinases. Nucleus (United States) 5: 224-236

Chauve L, Le Pen J, Hodge F, Todtenhaupt P, Biggins L, Miska EA, Andrews S \& Casanueva O (2020) Highthroughput quantitative RT-PCR in single and bulk C. Elegans samples using nanofluidic technology. J Vis Exp 2020: 1-12

Coin F, Bergmann E, Tremeau-Bravard A \& Egly JM (1999) Mutations in XPB and XPD helicases found in xeroderma pigmentosum patients impair the transcription function of TFIIH. EMBO J 18: 13571366

Coin F, De Santis LP, Nardo T, Zlobinskaya O, Stefanini M \& Egly JM (2006) p8/TTD-A as a repair-specific TFIIH subunit. Mol Cell 21: 215-226

Compe E \& Egly JM (2016) Nucleotide Excision Repair and Transcriptional Regulation: TFIIH and beyond. Annu Rev Biochem 85: 265-290

Compe E, Genes CM, Braun C, Coin F \& Egly JM (2019) TFIIE orchestrates the recruitment of the TFIIH kinase module at promoter before release during transcription. Nat Commun 10: 1-14 
Corbett MA, Dudding-Byth T, Crock PA, Botta E, Christie LM, Nardo T, Caligiuri G, Hobson L, Boyle J, Mansour A, et al (2015) A novel X-linked trichothiodystrophy associated with a nonsense mutation in RNF113A. J Med Genet 52: 269-274

Dokshin GA, Ghanta KS, Piscopo KM \& Mello CC (2018) Robust genome editing with short singlestranded and long, partially single-stranded DNA donors in caenorhabditis elegans. Genetics 210: 781-787

Donnio LM, Miquel C, Vermeulen W, Giglia-Mari G \& Mari PO (2019) Cell-type specific concentration regulation of the basal transcription factor TFIIH in XPBy/y mice model. Cancer Cell Int 19

Faghri S, Tamura D, Kraemer KH \& DiGiovanna JJ (2008) Trichothiodystrophy: A systematic review of 112 published cases characterises a wide spectrum of clinical manifestations. J Med Genet 45: 609-621

Ferri D, Orioli D \& Botta E (2020) Heterogeneity and overlaps in nucleotide excision repair disorders. Clin Genet 97: 12-24

Fischer L, Gerard M, Chalut C, Lutz Y, Humbert S, Kanno M, Chambon P \& Egly JM (1992) Cloning of the 62-kilodalton component of basic transcription factor BTF2. Science (80- ) 257: 1392-1395

Fishburn J, Tomko E, Galburt E \& Hahn S (2015) Double-stranded DNA translocase activity of transcription factor TFIIH and the mechanism of RNA polymerase II open complex formation. PNAS 112: $3961-3966$

Geijer ME, Zhou D, Selvam K, Steurer B, Mukherjee C, Evers B, Cugusi S, Van Toorn M, van der Woude M, Janssens RC, et al (2021) Elongation factor ELOF1 drives transcription-coupled repair and prevents genome instability. Nat Cell Biol: accepted

Giglia-Mari G, Coin F, Ranish JA, Hoogstraten D, Theil A, Wijgers N, Jaspers NGJ, Raams A, Argentini M, 
Van Der Spek PJ, et al (2004) A new, tenth subunit TFIIH is responsible for the DNA repair syndrome trichothiodystrophy group A. Nat Genet 36: 714-719

Giglia-Mari G, Miquel C, Theil AF, Mari PO, Hoogstraten D, Ng JMY, Dinant C, Hoeijmakers JHJ \& Vermeulen W (2006) Dynamic interaction of TTDA with TFIIH is stabilized by nucleotide excision repair in living cells. PLOS Biol 4: 0952-0963

Hartman PS, Hevelone J, Dwarakanath V \& Mitchell DL (1989) Excision repair of UV radiation-induced DNA damage in Caenorhabditis elegans. Genetics 122: 379-385

Hashimoto S \& Egly JM (2009) Trichothiodystrophy view from the molecular basis of DNA repair/transcription factor TFIIH. Hum Mol Genet 18: 224-230

Hoogstraten D, Nigg AL, Heath H, Mullenders LHF, Van Driel R, Hoeijmakers JHJ, Vermeulen W \& Houtsmuller AB (2002) Rapid switching of TFIIH between RNA polymerase I and II transcription and DNA repair in vivo. Mol Cell 10: 1163-1174

Iben S, Tschochner H, Bier M, Hoogstraten D, Hozák P, Egly JM \& Grummt I (2002) TFIIH plays an essential role in RNA polymerase I transcription. Cell 109: 297-306

Kainov DE, Vitorino M, Cavarelli J, Poterszman A \& Egly JM (2008) Structural basis for group A trichothiodystrophy. Nat Struct Mol Biol 15: 980-984

Kamath RS, Fraser AG, Dong Y, Poulin G, Durbin R, Gotta M, Kanapin A, Le Bot N, Moreno S, Sohrmann M, et al (2003) Systematic functional analysis of the Caenorhabditis elegans genome using RNAi. Nature 421: 231-237

Kappenberger J, Koelmel W, Schoenwetter E, Scheuer T, Woerner J, Kuper J \& Kisker C (2021) How to limit the speed of a motor: The intricate regulation of the XPB ATPase and translocase in TFIIH. 
Nucleic Acids Res 48: 12282-12296

Karikkineth AC, Scheibye-Knudsen M, Fivenson E, Croteau DL \& Bohr VA (2017) Cockayne syndrome:

Clinical features, model systems and pathways. Ageing Res Rev 33: 3-17

Keriel A, Stary A, Sarasin A, Rochette-Egly C \& Egly JM (2002) XPD mutations prevent TFIIH-dependent transactivation by nuclear receptors and phosphorylation of RAR $\alpha$. Cell 109: 125-135

Kuo ME, Theil AF, Kievit A, Malicdan MC, Introne WJ, Christian T, Verheijen FW, Smith DEC, Mendes MI, Hussaarts-Odijk L, et al (2019) Cysteinyl-tRNA Synthetase Mutations Cause a Multi-System, Recessive Disease That Includes Microcephaly, Developmental Delay, and Brittle Hair and Nails. Am J Hum Genet 104: 520-529

Kuschal C, Botta E, Orioli D, Digiovanna JJ, Seneca S, Keymolen K, Tamura D, Heller E, Khan SG, Caligiuri G, et al (2016) GTF2E2 Mutations Destabilize the General Transcription Factor Complex TFIIE in Individuals with DNA Repair-Proficient Trichothiodystrophy. Am J Hum Genet 98: 627-642

Lans H, Hoeijmakers JHJ, Vermeulen W \& Marteijn JA (2019) The DNA damage response to transcription stress. Nat Rev Mol Cell Biol 20: 766-784

Lans H \& Jansen G (2007) Multiple sensory G proteins in the olfactory, gustatory and nociceptive neurons modulate longevity in Caenorhabditis elegans. Dev Biol 303: 474-482

Lans H, Lindvall JM, Thijssen K, Karambelas AE, Cupac D, Fensgård O, Jansen G, Hoeijmakers JHJ, Nilsen H \& Vermeulen W (2013) DNA damage leads to progressive replicative decline but extends the life span of long-lived mutant animals. Cell Death Differ 20: 1709-1718

Lans H, Marteijn JA, Schumacher B, Hoeijmakers JHJ, Jansen G \& Vermeulen W (2010) Involvement of global genome repair, transcription coupled repair, and chromatin remodeling in UV DNA damage 
response changes during developm. PLoS Genet 6: 41

Lans H \& Vermeulen W (2011) Nucleotide Excision Repair in Caenorhabditis elegans . Mol Biol Int 2011: $1-12$

Lans H \& Vermeulen W (2015) Tissue specific response to DNA damage: C. elegans as role model. DNA Repair (Amst) 32: 141-148

Lee MH, Ahn B, Choi IS \& Koo HS (2002) The gene expression and deficiency phenotypes of Cockayne syndrome B protein in Caenorhabditis elegans. FEBS Lett 522: 47-51

Lehmann AR (2003) DNA repair-deficient diseases, xeroderma pigmentosum, Cockayne syndrome and trichothiodystrophy. Biochimie 85: 1101-1111

Lu H, Zawel L, Fisher L, Egly JM \& Reinberg D (1992) Human general transcription factor IIH phosphorylates the C-terminal domain of RNA polymerase II. Nature 358: 641-645

Luo J, Cimermancic P, Viswanath S, Ebmeier CC, Kim B, Dehecq M, Raman V, Greenberg CH, Pellarin R, Sali A, et al (2015) Architecture of the Human and Yeast General Transcription and DNA Repair Factor TFIIH. Mol Cell 59: 794-806

Marteijn JA, Lans H, Vermeulen W \& Hoeijmakers JHJ (2014) Understanding nucleotide excision repair and its roles in cancer and ageing. Nat Rev Mol Cell Biol 15: 465-481

Meyer JN, Boyd WA, Azzam GA, Haugen AC, Freedman JH \& Van Houten B (2007) Decline of nucleotide excision repair capacity in aging Caenorhabditis elegans. Genome Biol 8: R70

Minn IL, Rolls MM, Hanna-Rose W \& Malone CJ (2009) SUN-1 and ZYG-12, mediators of centrosomenucleus attachment, are a functional SUN/KASH pair in Caenorhabditis elegans. Mol Biol Cell 20: 4586-4595 
Mitani S (2009) Nematode, an experimental animal in the National BioResource Project. Exp Anim 58: $351-356$

Moriwaki S, Saruwatari H, Kanzaki T, Kanekura T \& Minoshima S (2014) Trichothiodystrophy group A: A first Japanese patient with a novel homozygous nonsense mutation in the GTF2H5 gene. J Dermatol 41: 705-708

Nonnekens J, Cabantous S, Slingerland J, Mari PO \& Giglia-Mari G (2013) In vivo interactions of TTDA mutant proteins within TFIIH. J Cell Sci 126: 3278-3283

Ohkuma Y \& Roeder RG (1994) Regulation of TFIIH ATPase and kinase activities by TFIIE during active initiation complex formation. Nature 368: 160-163

Park CH, Mu D, Reardon JT \& Sancar A (1995) The general transcription-repair factor TFIIH is recruited to the excision repair complex by the XPA protein independent of the TFIIE transcription factor. J Biol Chem 270: 4896-4902

Park E, Guzder SN, Koken MHM, Jaspers-Dekker I, Weeda G, Hoeijmakers JHJ, Prakash S \& Prakash L (1992) RAD25 (SSL2), the yeast homolog of the human xeroderma pigmentosum group B DNA repair gene, is essential for viability. Proc Natl Acad Sci U S A 89: 11416-11420

Park HK, Suh D, Hyun M, Koo HS \& Ahn B (2004) A DNA repair gene of Caenorhabditis elegans: A homolog of human XPF. DNA Repair (Amst) 3: 1375-1383

Ranish JA, Hahn S, Lu Y, Yi EC, Li XJ, Eng J \& Aebersold R (2004) Identification of TFB5, a new component of general transcription and DNA repair factor IIH. Nat Genet 36: 707-713

Ribeiro-Silva C, Aydin ÖZ, Mesquita-Ribeiro R, Slyskova J, Helfricht A, Marteijn JA, Hoeijmakers JHJ, Lans H \& Vermeulen W (2018) DNA damage sensitivity of SWI/SNF-deficient cells depends on TFIIH 
subunit p62/GTF2H1. Nat Commun 9: 4067

Rieckher M, Bujarrabal A, Doll MA, Soltanmohammadi N \& Schumacher B (2017) A simple answer to complex questions: Caenorhabditis elegans as an experimental model for examining the DNA damage response and disease genes. J Cell Physiol 233: 2781-2790

Sabatella M, Theil AF, Ribeiro-Silva C, Slyskova J, Thijssen K, Voskamp C, Lans H \& Vermeulen W (2018) Repair protein persistence at DNA lesions characterizes XPF defect with Cockayne syndrome features. Nucleic Acids Res 46: 9563-9577

Sabatella M, Thijssen KL, Davó-Martínez C, Vermeulen W \& Lans H (2021) Tissue-Specific DNA Repair Activity of ERCC-1/XPF-1. Cell Rep 34: 108608

Salamov AA \& Solovyev V V. (2000) Ab initio gene finding in Drosophila genomic DNA. Genome Res 10: $516-522$

Schärer OD (2013) Nucleotide excision repair in Eukaryotes. Cold Spring Harb Perspect Bio/ 5

Singh A, Compe E, Le May N \& Egly JM (2015) TFIIH subunit alterations causing xeroderma pigmentosum and trichothiodystrophy specifically disturb several steps during transcription. Am J Hum Genet 96: 194-207

Stergiou L, Doukoumetzidis K, Sendoel A \& Hengartner MO (2007) The nucleotide excision repair pathway is required for UV-C-induced apoptosis in Caenorhabditis elegans. Cell Death Differ 14: $1129-1138$

Steurer B, Janssens RC, Geverts B, Geijer ME, Wienholz F, Theil AF, Chang J, Dealy S, Pothof J, Van Cappellen WA, et al (2018) Live-cell analysis of endogenous GFP-RPB1 uncovers rapid turnover of initiating and promoter-paused RNA Polymerase II. Proc Natl Acad Sci U S A 115: E4368-E4376 
Sugasawa K, Akagi J ichi, Nishi R, Iwai S \& Hanaoka F (2009) Two-Step Recognition of DNA Damage for Mammalian Nucleotide Excision Repair: Directional Binding of the XPC Complex and DNA Strand Scanning. Mol Cell 36: 642-653

Tessarech M, Gorce M, Boussion F, Bault JP, Triau S, Charif M, Khiaty S, Delorme B, Guichet A, Ziegler A, et al (2020) Second report of RING finger protein 113A (RNF113A) involvement in a Mendelian disorder. Am J Med Genet Part A 182: 565-569

Theil AF, Botta E, Raams A, Smith DEC, Mendes MI, Caligiuri G, Giachetti S, Bione S, Carriero R, Liberi G, et al (2019) Bi-allelic TARS Mutations Are Associated with Brittle Hair Phenotype. Am J Hum Genet 105: $434-440$

Theil AF, Hoeijmakers JHJ \& Vermeulen W (2014) TTDA: Big impact of a small protein. Exp Cell Res 329: 61-68 doi:10.1016/j.yexcr.2014.07.008 [PREPRINT]

Theil AF, Mandemaker IK, van den Akker E, Swagemakers SMA, Raams A, Wüst T, Marteijn JA, Giltay JC, Colombijn RM, Moog U, et al (2017) Trichothiodystrophy causative TFIIE $\beta$ mutation affects transcription in highly differentiated tissue. Hum Mol Genet 26: 4689-4698

Theil AF, Nonnekens J, Steurer B, Mari PO, de Wit J, Lemaitre C, Marteijn JA, Raams A, Maas A, Vermeij M, et al (2013) Disruption of TTDA Results in Complete Nucleotide Excision Repair Deficiency and Embryonic Lethality. PLoS Genet 9: 1003431

Theil AF, Nonnekens J, Wijgers N, Vermeulen W \& Giglia-Mari G (2011) Slowly Progressing Nucleotide Excision Repair in Trichothiodystrophy Group A Patient Fibroblasts. Mol Cell Biol 31: 3630-3638

Tirode F, Busso D, Coin F \& Egly JM (1999) Reconstitution of the transcription factor TFIIH: Assignment of functions for the three enzymatic subunits, XPB, XPD, and cdk7. Mol Cell 3: 87-95 
Vermeulen W, Bergmann E, Auriol J, Rademakers S, Frit P, Appeldoorn E, Hoeijmakers JHJ \& Egly JM

(2000) Sublimiting concentration of TFIIH transcription/DNA repair factor causes TTD-A

trichothiodystrophy disorder. Nat Genet 26: 307-313

Wang Y, Chakravarty P, Ranes M, Kelly G, Brooks PJ, Neilan E, Stewart A, Schiavo G \& Svejstrup JQ (2014)

Dysregulation of gene expression as a cause of cockayne syndrome neurological disease. Proc Natl

Acad Sci U S A 111: 14454-14459

Winkler GS, Araújo SJ, Fiedler U, Vermeulen W, Coin F, Egly JM, Hoeijmakers JHJ, Wood RD, Timmers

HTM \& Weeda G (2000) TFIIH with inactive XPD helicase functions in transcription initiation but is defective in DNA repair. J Biol Chem 275: 4258-4266

van der Woude M \& Lans H (2021) C. elegans survival assays to discern global and transcription-coupled nucleotide excision repair. STAR Protoc Accepted

Yamamoto S, Watanabe Y, van der Spek PJ, Watanabe T, Fujimoto H, Hanaoka F \& Ohkuma Y (2001) Studies of Nematode TFIIE Function Reveal a Link between Ser-5 Phosphorylation of RNA Polymerase II and the Transition from Transcription Initiation to Elongation. Mol Cell Biol 21: 1-15

Zhang D, Tu S, Stubna M, Wu WS, Huang WC, Weng Z \& Lee HC (2018) The piRNA targeting rules and the resistance to piRNA silencing in endogenous genes. Science (80- ) 359: 587-592

Zhang L, Ward JD, Cheng Z \& Dernburg AF (2015) The auxin-inducible degradation (AID) system enables versatile conditional protein depletion in C. elegans. Dev 142: 4374-4384 
A

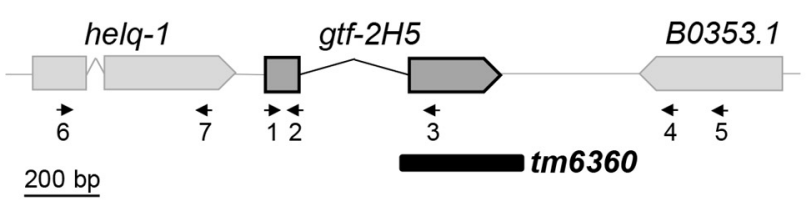

B

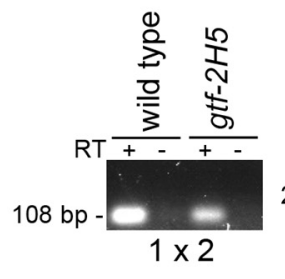

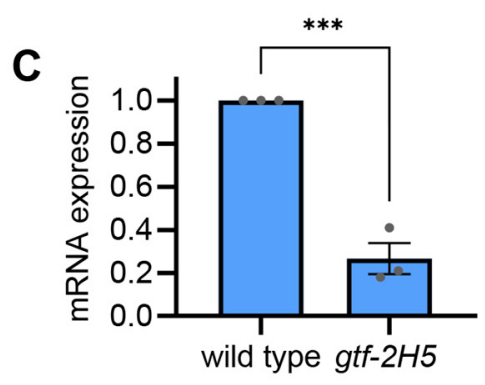

D

wild type MVNVKKGVLVTSDPAFRQLLIHLDDSRQLGSKFIVRELDDTHLFIEKEIVPMLENKVEQIMENMNPEAVDK* tm6360 MVNVKKGVLVTSDPAFRQLLIHLDDSRQLGSKFIVRALVPRGARCNASSFALDSRM*

Figure 1. The gtf-2H5(tm6360) allele encodes a truncated protein.

A. Schematic depiction of $g t f-2 H 5$ locus with parts of flanking genes helq-1 and B0353.1. Numbered arrows indicate positions of primers used in RT-(q)PCR. Primer sequences are listed in Table EV2. The deletion of the $\operatorname{tm} 6360$ allele is indicated with a black box.

B. PCR with primer pairs $1 \times 2$ or $1 \times 3$, as indicated in A, on cDNA of wild type or gtf- $2 \mathrm{H} 5$ animals. Lanes containing cDNA generated by reverse transcription of mRNA are labeled with ' + '. As control, PCR on cDNA reaction samples without reverse transcriptase (RT) were included, labeled with '-'.

C. Relative mRNA expression levels of exon 1 of the $g t f-2 H 5$ transcript as determined by qPCR on wild type and gtf-2H5 mutant animals. mRNA levels were normalized to wild type. Results are plotted as average with SEM (error bars) of three independent experiments. Statistically significant difference $(<0.001)$ is indicated by $* * *$.

D. Amino acid sequence of wild type GTF-2H5 and of the truncated protein predicted to be expressed by the tm6360 gtf-2H5 allele. Red color indicate sequence that deviates from wild type. 


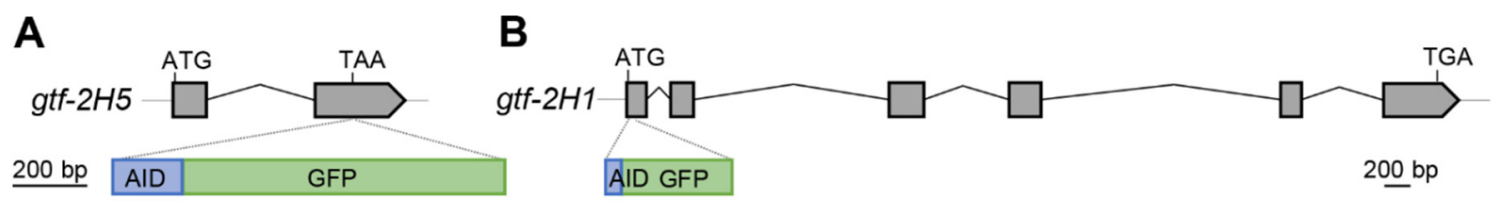

C

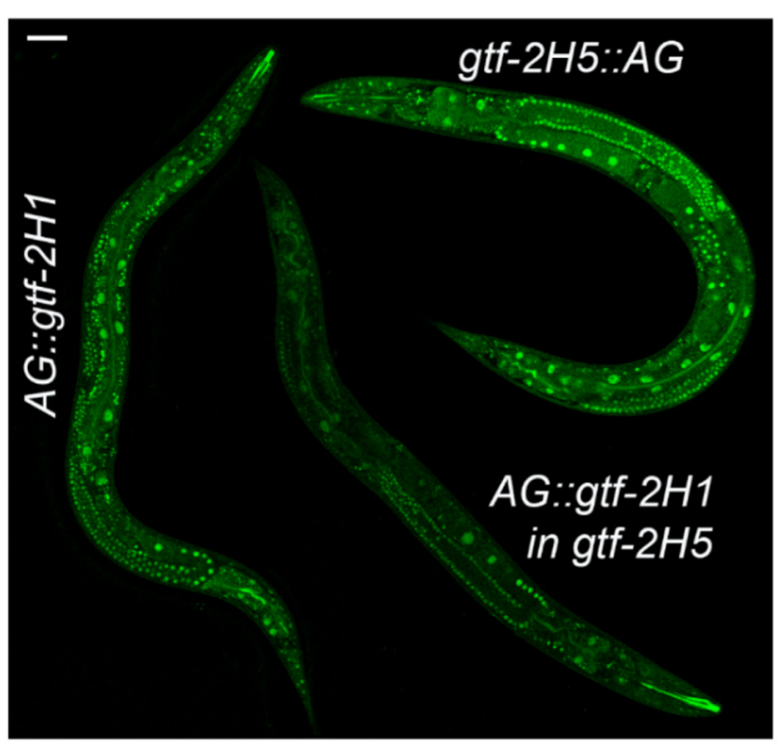

\section{D}

gtf-2H5::AG sun-1::TIR1

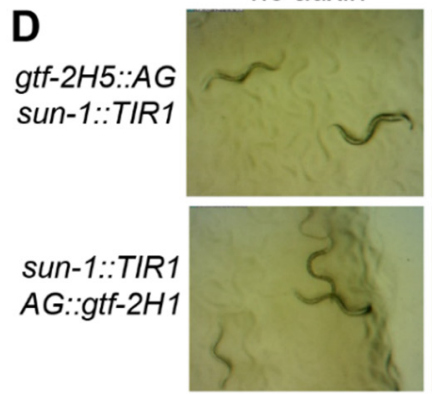

sun-1::TIR1 $A G:: g t f-2 H 1$

no auxin

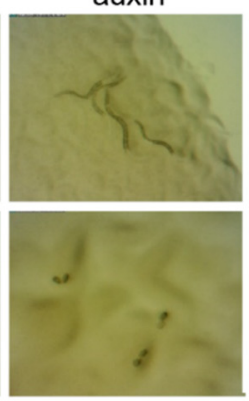

$E$

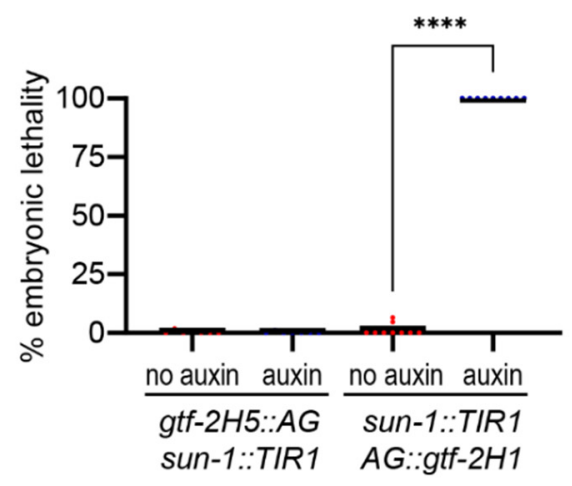

$\mathbf{F}$ oocytes
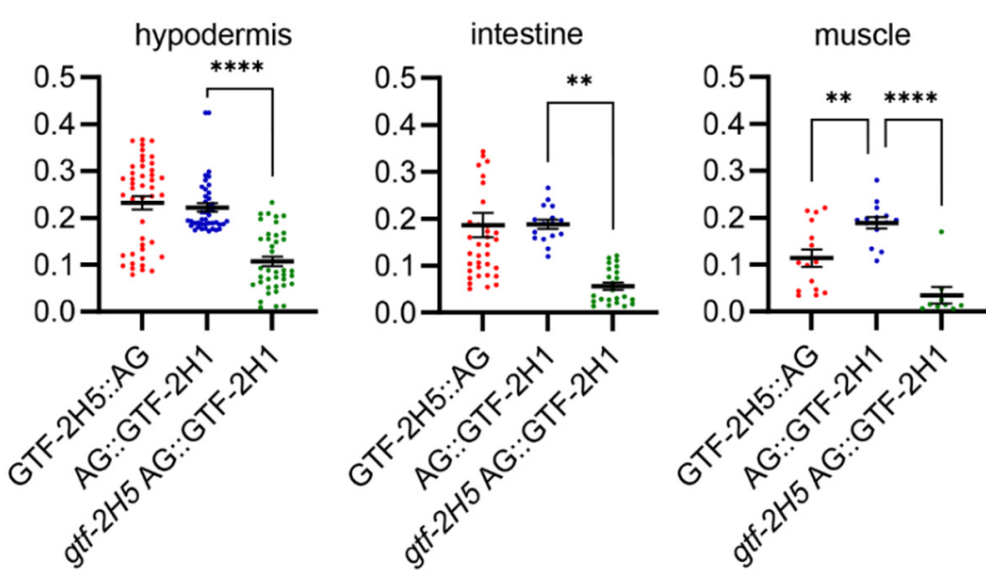

Figure 2. GTF-2H5 and GTF-2H1 are ubiquitously expressed but at different concentrations.

A. Schematic depiction of the gtf-2H5 locus and C-terminal knockin site of the AID::GFP tag.

B. Schematic depiction of the gtf-2H1 locus and N-terminal knockin site of the AID::GFP tag. 
C. Composite overview image generated by merging independent confocal scans of gtf-2H5::AG, AG::gtf-

$2 H 1$ and $g t f-2 H 5 ; A G:: g t f-2 H 1$. Scale bar: $50 \mu \mathrm{m}$.

D. Stereo microscope view of the offspring of $g t f-2 H 5:: A G$ and $A G:: g t f-2 H 1$ animals expressing TIR1 under control of the sun-1 promoter grown in absence or presence of $1 \mathrm{mM}$ auxin. Only auxin-induced depletion of $A G:: g t f-2 H 1$ leads to embryonic lethality.

E. Quantification of the experiment described in D. Shown is a scatter dot plot of the average percentage embryonic lethality observed on at least seven plates for each condition in two independent experiments. Statistically significant difference $(<0.0001)$ is indicated by $* * * *$.

F. Quantification of GTF-2H5::AG and AG::GTF-2H1 concentration in nuclei of oocytes, hypodermal, intestinal and muscles cells of wild type and gtf-2H5 animals. Concentration was determined by comparison of the average fluorescence levels in the entire nucleus to the fluorescence of known concentrations of purified GFP. 
A

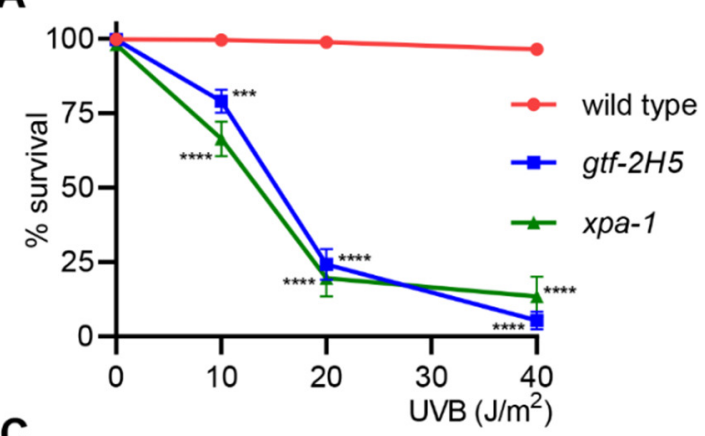

C

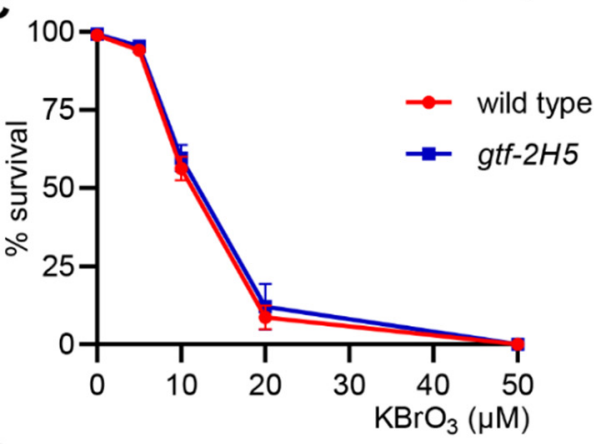

D

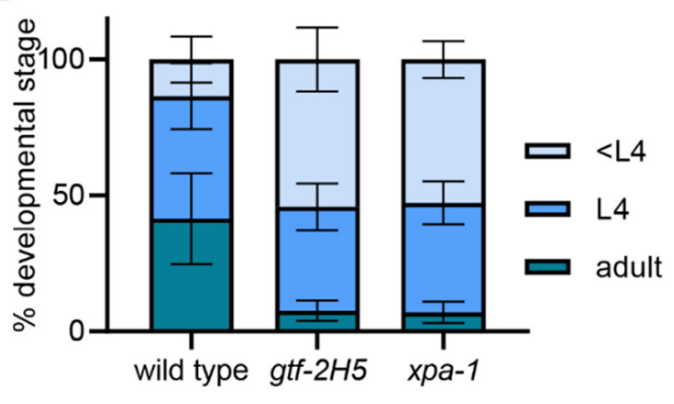

B

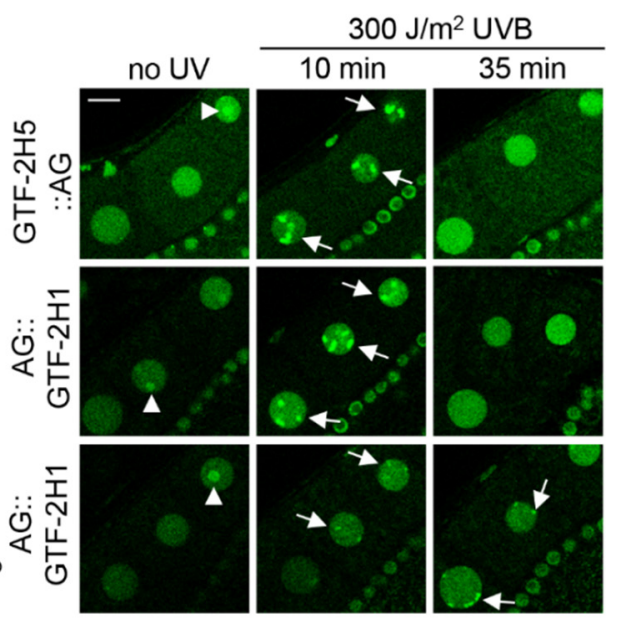

$\mathbf{E}$
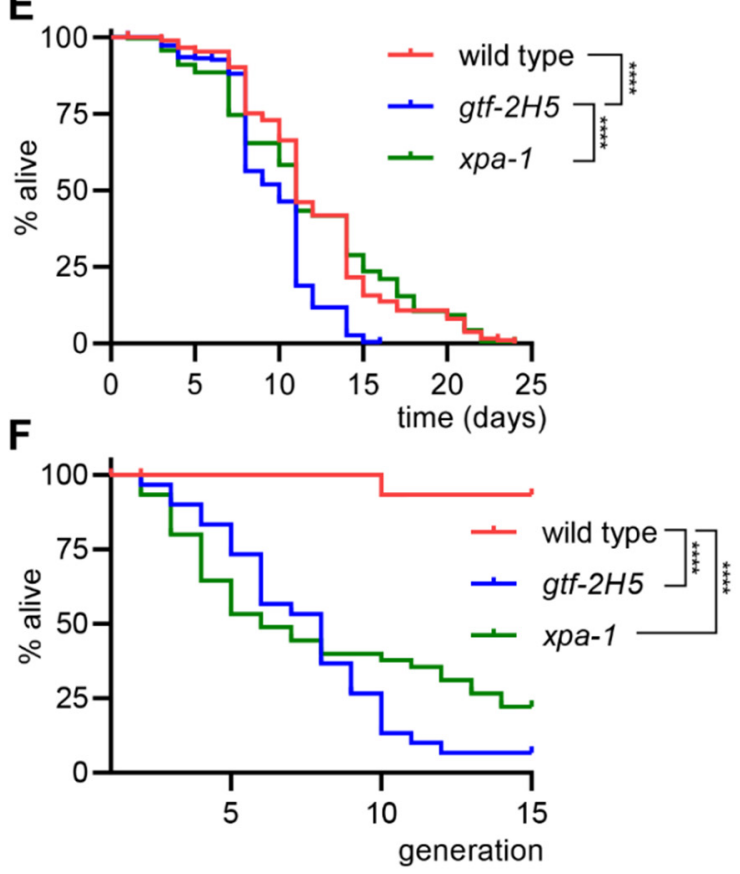

Figure 3. gtf-2H5 animals are NER deficient and show diminished growth and lifespan

A. Germ cell and embryo survival assay after UVB irradiation of germ cells in young adult wild type, gtf$2 \mathrm{H} 5$ and $x p a-1$ animals. The percentages of hatched eggs (survival) after UVB irradiation are plotted against the applied UV-B doses. Results are plotted as average with SEM (error bars) of at least six experiments. Statistically significant difference compared to wild type for each dose is indicated by *** $(<0.001)$ or $* * * *(<0.0001)$. 
B. Representative images showing real-time recruitment of GTF-2H5::AG or AG::GTF-2H1 to UVBdamaged chromosomes in oocytes of living wild type (upper and middle panel) or gtf-2H5 (lower panel) animals, before UVB irradiation (no UV) and $10 \mathrm{~min}$ and $35 \mathrm{~min}$ after $300 \mathrm{~J} / \mathrm{m}^{2}$ UVB irradiation. Recruitment to paired homologous chromosomes are indicated with arrows. Nucleoli are indicated with an arrowhead. Scale bar: $10 \mu \mathrm{m}$

C. Survival assay after incubation of wild type and gtf-2H5 L1/L2 larvae with increasing concentrations of $\mathrm{KBrO}_{3}$ for $24 \mathrm{~h}$, which induces oxidative DNA damage. The percentages of non-arrested, developing larvae (survival) are plotted against the applied $\mathrm{KBrO}_{3}$ concentration. Results are plotted as average with SEM (error bars) of two independent experiments each performed in triplicate.

D. Quantification of larval growth of wild type, $g t f-2 \mathrm{H} 5$ and $x p a-1$ animals by determining the percentage of adult, $\mathrm{L} 4$ and younger than L4 $(<\mathrm{L} 4)$ animals observed $48 \mathrm{~h}$ after animals are laid as eggs at $25^{\circ} \mathrm{C}$.

E. Post-mitotic lifespan analysis showing the percentage of alive adult wild type $(n=290), g t f-2 H 5(n=300)$ and xpa-1 $(\mathrm{n}=285)$ animals per day. Statistically significant difference $(<0.0001)$ is indicated by ****.

F. Replicative lifespan analysis showing the percentage survival of successive generations of wild type, gtf$2 \mathrm{H} 5$ and $x p a-1$ animals if, in each generation, one animal is passaged. Depicted are cumulative results from at least two independent experiments ( $n=15$ per experiment). Statistically significant difference $(<0.0001)$ is indicated by $* * * *$. 

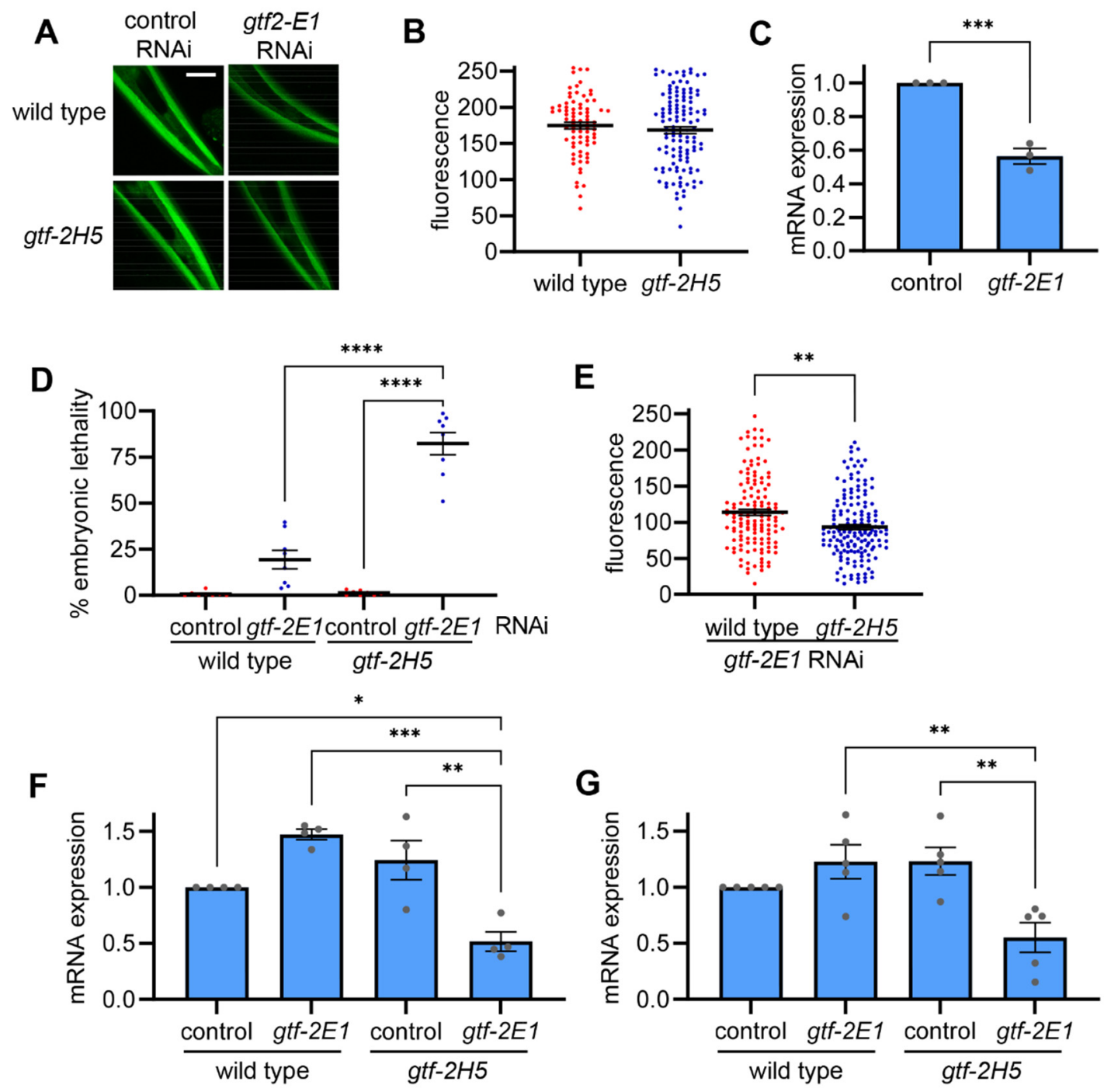

Figure 4. GTF-2H5 promotes transcription when this is challenged

A) Representative images of wild type and $g t f-2 H 5$ animals expressing AID::GFP under control of eft-3 promoter in body wall muscles, shown here in the head of $C$. elegans, grown on control or gtf-2E1 RNAi. Scale bar: $25 \mu \mathrm{m}$

B) Scatter dot plot showing average and SEM of the relative GFP fluorescence levels in head muscle cells of wild-type and $g t f-2 \mathrm{H} 5$ animals, as depicted in A. 
C) Relative gtf-2E1 mRNA levels as determined by qPCR on animals grown on control or gtf-2E1 RNAi.

Results are normalized to control RNAi and plotted as average with SEM (error bars) of three independent experiments. Statistically significant difference $(<0.001)$ is indicated by $* * *$.

D) Scatter dot plot showing the average percentage with SEM of embryonic lethality observed on eight plates in two independent experiments with either wild type animals or gtf-2H5 animals (both also carrying the eft-3::GFP transgene used in A and B, grown on control or gtf-2E1 RNAi food. Statistically significant differences are indicated by $* * * *(<0.0001)$.

E) Scatter dot plot showing average and SEM of the relative GFP fluorescence levels in head muscle cells of wild-type and gtf-2H5 animals grown on gtf-2E1 RNAi food, as depicted in A. Statistically significant differences are indicated by $* *(<0.01)$.

F) Relative $c d c-42$ mRNA levels as determined by qPCR on wild type or gtf-2H5 animals grown on control or gtf-2E1 RNAi. Results are normalized to wild type on control RNAi and plotted as average with SEM (error bars) of four independent experiments. Statistically significant difference is indicated by * $(<0.05)$, $* *(<0.01)$ or $* * *(<0.001)$.

G) Relative $p m p-3$ mRNA levels as determined by qPCR on wild type or $g t f-2 \mathrm{H} 5$ animals grown on control or gtf-2E1 RNAi. Results are normalized to wild type on control RNAi and plotted as average with SEM (error bars) of five independent experiments. Statistically significant differences are indicated by ** $(<0.01)$. 

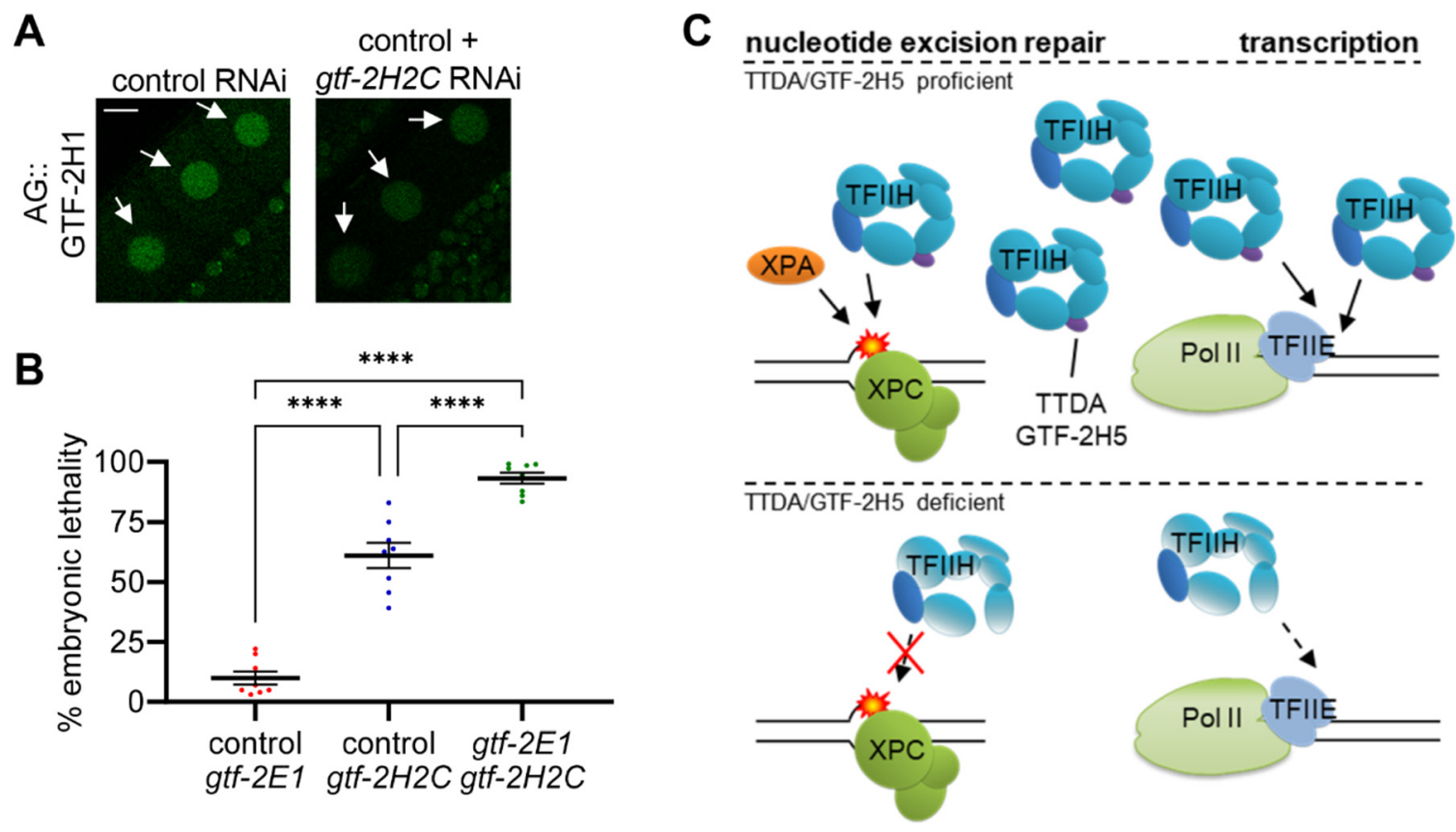

Figure 5. Synthetic lethality between GTF-2H2C and GTF-2E1 and model for GTF-2H5 activity

A) Representative images of AG::GTF-2H1 fluorescence in oocyte nuclei (indicated by arrows) of $A G:: g t f$ $2 \mathrm{H} 1$ knockin animals grown on control RNAi or a 1:1 mixture of control and gtf-2H2C RNAi food. Scale bar: $10 \mu \mathrm{m}$

B) Scatter dot plot showing the average percentage with SEM of embryonic lethality observed on eight plates in two independent experiments with wild type animals grown on 1:1 mixtures of control RNAi with gtf-2E1 RNAi food, control RNAi with gtf-2H2C RNAi food or gtf-2E1 RNAi and gtf-2H2C RNAi food.

C) Model for TTDA/GTF-2H5 involvement in nucleotide excision repair and transcription initiation. In wild type cells (upper part), TTDA/GTF-2H5 is the smallest subunit of a fully functional TFIIH complex, which exists in sufficiently high concentrations to promote nucleotide excision repair together with XPC and XPA and transcription initiation by RNA polymerase II (Pol II) together with TFIIE (and other not depicted repair and transcription factors). In TTDA/GTF-2H5 deficient cells (lower part), the TFIIH complex is not efficiently 
bioRxiv preprint doi: https://doi.org/10.1101/2021.06.04.447037; this version posted June 4, 2021. The copyright holder for this preprint (which was not certified by peer review) is the author/funder, who has granted bioRxiv a license to display the preprint in perpetuity. It is made available under aCC-BY-ND 4.0 International license.

recruited and active in nucleotide excision repair. Also, as the complex is unstable and exists in low concentrations, it can only support transcription initiation if this is not too demanding. 
Table 1. C. elegans TFIIH subunits

$\begin{array}{ll}\text { C. elegans gene } & \text { human ortholog } \\ x p b-1 & \text { ERCC3 (XPB) } \\ \text { xpd-1 } & \text { ERCC2 (XPD) } \\ \text { gtf-2H1 } & \text { GTF2H1 (p62) } \\ \text { gtf-2H2C } & \text { GTF2H2 (p44) } \\ \text { gtf-2H3 } & \text { GTF2H3 (p34) } \\ \text { gtf-2H4 } & \text { GTF2H4 (p52) } \\ \text { gtf-2H5 } & \text { GTF2H5 (p8) } \\ \text { mnat-1 } & \text { MNAT1 (MAT1) } \\ \text { cyh-3 } & \text { CCNH (Cyclin H) } \\ \text { cdk-7 } & \text { CDK7 }\end{array}$

Table 2. Brood size of wild type and gtf-2H5 animals

strain

wild type

gtf-2H5(tm6360) average $\pm \operatorname{sem}(n)$

brood size

$215 \pm 14(n=20)$

$212 \pm 8(n=20)$ 